\title{
ESTUDO DE VISIBILIDADE EM SISTEMAS DE TRANSMISSÃO DE ENERGIA - ANÁLISE DE INTERVENÇÃO NA PAISAGEM DA COXILHA RICA
}

Vivian da Silva Celestino Reginato ${ }^{1}$ Samuel Abati ${ }^{2}$

Resumo: O Caminho das Tropas são estruturas remanescentes de importantes vias terrestres construídas e utilizadas no Brasil Colônia durante os séculos XVIII, XIX e XX. A região da Coxilha Rica, em Santa Catarina, possui muitos remanescentes destas vias e devido ao seu grande potencial hidrológico, na década de 2000, muitas empresas buscaram construir Pequenas Centrais Hidrelétricas nos muitos rios existentes na região. Como forma de preservar o ambiente cênico da região, por causa de seu potencial turístico e paisagístico, o Instituto do Patrimônio Histórico e Artístico Nacional (IPHAN) solicitou aos empreendedores estudos de paisagem a fim de minimizar os impactos advindos da inserção de sistemas de transmissão. Neste sentido o objetivo principal deste trabalho é apresentar o método de geração de poligonais de visibilidade a partir de elementos históricos da Região da Coxilha Rica, visando eliminar ou minimizar o impacto visual sobre o ambiente cênico devido a inserção de sistemas de transmissão de energia elétrica. O método consistiu em mapear a poligonal de visibilidade, levando em consideração a acuidade visual humana, a partir de pontos definidos como principais (fazendas históricas e corredores de taipas) e realizar análises espaciais. Através da realização de cruzamento de níveis de informação foi possível classificar e definir o grau de visibilidade da poligonal total, projetar os sistemas de transmissão e fornecer ao IPHAN subsídios para definir os melhores locais para realizar intervenções futuras de forma a preservar o ambiente cênico da região.

Palavras-chave: Paisagem. Caminho das tropas. Poligonal de visibilidade. Acuidade visual humana. Coxilha Rica.

\section{VISIBILITY STUDY APPLIED TO ENERGY TRANSMISSION SYSTEMS - INTERVENTION ANALYSIS IN "COXILHA RICA" LANDSCAPE}

\begin{abstract}
The Drovers' Path are remnant structures of important land routes built and used in Colonial Brazil during the $18^{\text {th }}, 19^{\text {th }}$ and $20^{\text {th }}$ centuries. The Coxilha Rica region in Santa Catarina has many remnants of these routes and due to its great hydrological potential, in the 2000s, many companies sought to build Small Hydroelectric Plants on many rivers in the region. As a way of preserving the region's scenic environment, because of its tourist and landscape potential, the National Historical and Artistic Heritage Institute (IPHAN) asked entrepreneurs for landscape studies and an end of time for the adverse effects of the insertion of streaming. In this context, the main objective of this work is to present the method of generating visibility from historical elements of the Coxilha Rica Region, removing or minimizing the visual impact on the scenic environment due to the insertion of electrical energy transmission systems. The method consisted of mapping the visibility polygonal,

\footnotetext{
${ }^{1}$ Universidade Federal de Santa Catarina (UFSC), Departamento de Engenharia Civil (ECV), Florianópolis, Brasil, vivian.celestino@ufsc.br, https://orcid.org/0000-0003-3543-7977

${ }^{2}$ Companhia de Geração e Transmissão de Energia Elétrica do Sul do Brasil (CGT Eletrosul), Departamento de Gestão Ambiental e Fundiária (DEA), Florianópolis, Brasil, samuelabati@gmail.com, https://orcid.org/0000-0003-0157-026X
} 
taking human visual acuity into consideration, from points related as main (historical farms and stone-walled corridors) and performing spatial analyzes. Through the crossing of levels of information, it was possible to classify and define the degree of visibility of the total polygonal, designing transmission systems and provide IPHAN with subsidies to define the best places to carry out the next steps in order to preserve the scenic environment of the region.

Keywords: Landscape. Drovers' Path. Visibility polygon. Human Visual Acuity. "Coxilha Rica".

\section{ESTUDIO DE VISIBILIDAD APLICADO A LOS SISTEMAS DE TRANSMISIÓN DE ENERGÍA - ANÁLISIS DE INTERVENCIÓN EN EL PAISAJE DE "COXILHA RICA"}

Resumen: El Camino de las Tropas ("Caminho das Tropas", en portugués) son estructuras remanentes de importantes vías terrestres construidas y utilizadas en el Brasil Colonia durante los siglos XVIII, XIX y XX. La región de Coxilha Rica en Santa Catarina tiene muchos restos de estas rutas y debido a su gran potencial hidrológico, en la década de 2000, muchas empresas buscaron construir pequeñas centrales hidroeléctricas en los numerosos ríos de la región. Como una forma de preservar el entorno escénico de la región, debido a su potencial turístico y paisajístico, el Instituto do Patrimônio Histórico e Artístico Nacional (IPHAN) solicitó a los empresarios estudios de paisaje para minimizar los impactos derivados de la inserción de sistemas de transmisión. En este sentido, el objetivo principal de este trabajo es presentar el método de generación de polígono de visibilidad a partir de elementos históricos de la Región de Coxilha Rica, con el objetivo de eliminar o minimizar el impacto visual en el entorno escénico debido a la inserción de sistemas de transmisión de energía eléctrica. El método consistió en cartografiar el polígono o grafo de visibilidad, teniendo en cuenta la agudeza visual humana, a partir de puntos definidos como principales (fincas históricas y muros de piedras) y realizar análisis espaciales. Al cruzar los niveles de información, fue posible clasificar y definir el grado de polígono de visibilidad total, diseñar los sistemas de transmisión y proporcionar a IPHAN subsidios para definir los mejores lugares para llevar a cabo futuras intervenciones con el fin de preservar el entorno escénico de la región.

Palabras clave: Paisaje. Camino de las tropas. Polígono de visibilidad. Agudeza visual humana. "Coxilha Rica".

\section{Introdução}

$\mathrm{Na}$ época do Brasil Colônia, por volta do século XVIII, importantes vias terrestres foram construídas e utilizadas até meados do século XX com a finalidade de transportar tropas de muares e bovinos para abastecimento comercial entre o Rio Grande do Sul e a região das minas de ouro, passando por Sorocaba (São Paulo) e pelos Campos de Lages em Santa Catarina [...] A este período de manifestação cultural, com encontro de diferentes costumes e atividades econômicas, foi atribuído o termo Tropeirismo (ABATI et al, 2010).

Remanescentes históricos e culturais deste período estão presentes por toda uma região do Planalto Sul Catarinense, denominada Coxilha Rica, e devido à sua 
peculiaridade, o Instituto de Patrimônio Histórico e Artístico Nacional (IPHAN), responsável por preservar a diversidade das contribuições dos diferentes elementos que compõem a sociedade brasileira e seus ecossistemas, demonstrou preocupação com a preservação desses elementos na região, não somente pelo seu patrimônio histórico e cultural, com suas fazendas históricas, antigos corredores de taipas, gastronomia e campos cavalgáveis, mas também por seu destacado potencial hidrológico que tem despertado interesse dos empreendedores do setor de energia nas últimas décadas.

Aproximadamente $15 \%$ de toda a água doce existente no mundo está no Brasil, distribuída em nove grandes bacias hidrográficas, o que explica a matriz energética brasileira ser composta predominantemente por recursos hídricos. 0 cenário do parque gerador brasileiro em 2009 era reflexo desta abundância hídrica, sendo que as usinas hidrelétricas representavam 79\% dele (ANEEL, 2008). Apesar de serem consideradas eficientes para geração, as grandes usinas hidrelétricas causam um grande impacto ambiental, socioeconômico e paisagístico (GOLDEMBERG e LUCON, 2008).

No final dos anos 2000, a busca pela suficiência energética combinada à preocupação com o meio ambiente proporcionou o desenvolvimento de pesquisas na área de fontes renováveis de energia, dentre elas a energia eólica, a solar e a energia produzida por Pequenas Centrais Hidrelétricas ( $\mathrm{PCH})$.

A região da Coxilha Rica, que possui alguns dos principais rios que constituem nascentes do rio Uruguai, é formada por extensas áreas de campos e vales encaixados que drenam um grande volume de águas e proporcionam um rico potencial hidrelétrico, fato que chamou a atenção de muitos empreendedores do ramo de energia elétrica na década de 2000.

$\mathrm{Na}$ época de desenvolvimento desta pesquisa, a empresa CGT Eletrosul (Eletrosul Centrais Elétricas S.A. à época), assim como outros empreendedores, adquiriu os projetos de quatro $\mathrm{PCHs}$ na área da Coxilha Rica. $\mathrm{Na}$ fase de licenciamento ambiental, o IPHAN, preocupado com a preservação, solicitou que as empresas envolvidas nos empreendimentos desenvolvessem um método em conjunto para minimizar os impactos visuais a serem causados na área devido à inserção de sistemas de transmissão para transportar a energia gerada.

Sistemas de transmissão são compostos por estruturas metálicas e cabos que transportam eletricidade da unidade geradora aos centros consumidores e, em sua maioria, são interligados ao Sistema Interligado Nacional (SIN) (ANEEL, 2008). 
O estudo realizado proporcionou ao IPHAN subsídio para a análise e gestão da paisagem, bem como serviu para controlar as solicitações de intervenção no espaço em questão, não somente dos pedidos de licenciamento ambiental das empresas interessadas, mas também dos pedidos de licenciamentos futuros.

Devido a esta iniciativa, a pesquisa tornou-se relevante cientificamente por desenvolver metodologia de suporte, ferramenta e produtos cartográficos para tomada de decisão nas análises de intervenção na paisagem da Coxilha Rica por parte do IPHAN, pois sendo a área composta por grande quantidade de fazendas centenárias e caminhos das tropas, inserida em uma paisagem natural de grande beleza, torna-se propícia ao turismo rural.

Para atendimento às condicionantes ambientais, iniciaram-se as pesquisas históricas e estudos de viabilidade. Na época de desenvolvimento deste trabalho existia uma carência de fontes e referências relativas aos estudos de paisagem, principalmente as que envolvessem cartografia e métodos quantitativos que relacionassem o alcance visual humano à geração e definição de limite para produção cartográfica. Carecia, inclusive, de aparato teórico e bibliográfico acerca destes temas para realizar a gestão da paisagem.

O estado da arte em intervenção na paisagem se limitava à produção bibliográfica de Ana Clara Mourão Moura, o que embasou teoricamente todos os trabalhos desenvolvidos posteriormente. Especificamente, em Moura (2003) foi realizado um estudo acerca do planejamento urbano e gestão de patrimônio arquitetônico e urbanístico da Cidade de Ouro Preto, em Minas Gerais, onde a autora desenvolveu diferentes aplicações do geoprocessamento para o planejamento urbano: montagem de base de dados, conversão de dados, elaboração de Sistema de Informação Geográfica (SIG) e inserção dos conceitos de eixos visuais em SIG.

Com esta problemática posta, a limitação de métodos de estudos de paisagem e em atendimento aos condicionantes foram desenvolvidos estudos específicos, primeiramente para estimar o alcance visual humano e delimitar a área de abrangência dos subsequentes estudos e aplicações, bem como, em um segundo momento, foram desenvolvidos métodos para geração de poligonais de visibilidade, as consequentes análises espaciais e avaliações da qualidade.

As poligonais de visibilidade correspondem às porções da superfície visível no entorno de um observador, levando em consideração diversos fatores como a 
posição do observador, obstáculos no campo de visão, forma do relevo e acuidade visual humana.

Neste ínterim, o objetivo deste artigo é apresentar o método desenvolvido para gerar poligonais de visibilidade a partir dos elementos históricos da Região da Coxilha Rica, de forma a colaborar no processo de tomada de decisão em intervenção da paisagem, visando à eliminação ou minimização do impacto visual sobre o ambiente cênico da região, gerado por inserção de sistemas de transmissão de energia elétrica. Os objetivos específicos são:

- Apresentar o método desenvolvido para gerar poligonais de visibilidade na região da Coxilha Rica;

- Apresentar o método desenvolvido para avaliar a qualidade das poligonais de visibilidade geradas;

- Apresentar as propostas de inserção de sistemas de transmissão de energia.

\section{Conceituação teórica}

O termo paisagem pode ter várias conotações, dependendo da área de conhecimento na qual é estudada e pode evoluir desde um conceito objetivo, como a caracterização física do meio ambiente, ao subjetivo, como algo construído em contínua mudança e reflexo de um processo vivenciado. Estudar uma paisagem, como, por exemplo, a paisagem de um caminho usado por tropas de animais, militares e de pessoas, requer compreender que esta é uma construção cultural teórica feita no presente sobre as relações, a sociedade e um meio no passado.

As discussões e reflexões relativas à paisagem e da relação do homem com o meio ambiente tiveram seu desenvolvimento nos Estados Unidos e ganharam ênfase na Europa. Nas diretrizes operacionais para a implementação da Convenção do Patrimônio Mundial, em 1999, a UNESCO apresentou a ideia de paisagem cultural de maneira mais detalhada como sendo:

Paisagens culturais representam o trabalho combinado da natureza e do homem [...] são ilustrativas da evolução da sociedade e dos assentamentos humanos ao longo do tempo, sob a influência das determinantes físicas e/ou oportunidades apresentadas por seu ambiente natural e das sucessivas forças sociais, econômicas e culturais, tanto internas, quanto externas. Elas deveriam ser selecionadas com base tanto em seu extraordinário valor universal e sua representatividade em termos de região geocultural claramente definida, quanto por sua capacidade de ilustrar os elementos culturais essenciais e distintos daquelas regiões (UNESCO, 1999). 
Para Silva (2006), uma paisagem engloba elementos do passado, do presente e de projeções e perspectivas de futuro. De acordo com a autora, ao olhar a paisagem como uma janela, avistaremos elementos que tiveram sua história e significado em um período passado, compondo um espaço que determinado sujeito ou grupo vivenciou e elaborou. Naquele passado, esta espacialidade fez parte de uma paisagem diferente da que hoje vemos. Para Santos (1997) a paisagem é

“... onde, mediante acumulações e substituições, a ação das diferentes gerações se superpõe. $O$ espaço constitui a matriz sobre a qual as novas ações substituem as ações passadas. É ele, portanto, presente, porque passado e futuro" (SANTOS, 1997, p. 84).

No trabalho de Herberts (2009), a partir da perspectiva de analisar o Caminho das Tropas e as estruturas várias que compõem a paisagem do tropeirismo, a autora buscou compreender as transformações ocorridas, não no sentido das modificações físicas, mas a partir de uma perspectiva histórica de um processo de conquista e de ocupação de um território através de uma via antiga, conformando a constituição do que atualmente denomina-se de paisagem tropeirística.

De acordo com Abati et al (2010), o tropeirismo foi um ciclo econômico que deixou suas marcas no passado, construiu um ambiente formando a atual noção de paisagem tropeirística, que necessita ser entendida na contemporaneidade. Desta forma, procurou-se compreender a conduta humana no passado a partir da análise de mapas e suas relações do espaço no presente, unindo lógica, percepção e cognição em um mesmo espaço geográfico e atemporal.

Em relação à acuidade visual humana, de acordo com Celestino (2017), alguns fatores inerentes à natureza podem interferir na correta captação e percepção das imagens pelo ser humano. Quanto maior a quantidade de luz e menor a distância de observação, melhor será a imagem formada e menor será a influência dos efeitos atmosféricos, ou seja, as mudanças na velocidade da radiação, no comprimento de onda, na intensidade e na distribuição espectral. Um dos fenômenos que mais interfere a captação e percepção de imagens é a refração atmosférica. Outro fator físico que deve ser considerado é a curvatura terrestre.

De acordo com Celestino (2017), a percepção visual pode ser descrita através dos fenômenos lógicos, desde que alguns critérios sejam levados em consideração, como, por exemplo, escala, localização, altura de observação, esquemas lógicos, entre outros. Os esquemas lógicos são decorrentes da cultura, educação e idade, sendo o funcionamento esperado em níveis de percepção e de adaptação/aceitação e/ou inadaptação/rechaço. Os referenciais podem ser físicos (geográficos e 
simbólicos), culturais (religiosos e sociais) e psicológicos (significantes, singulares e constantes).

De acordo com Stolfi (2008), a percepção visual é um processo de reconstrução da realidade exterior, realizado pelo córtex cerebral, a partir de informações fragmentadas captadas pelos olhos. Através do nervo ótico que conduz os impulsos nervosos até o córtex cerebral, localizado na região occipital, se dá a imagem mental, e é recuperada então a terceira dimensão.

De acordo com Carmona et al (2006), a Acuidade Visual (AV) é a capacidade de discriminar os detalhes dos objetos no campo de visão, determinada pela dimensão mínima de alguns aspectos espaciais dos estímulos visuais, referindo-se ao limite espacial da discriminação visual. A AV depende das propriedades ópticas do olho (de gerar uma imagem precisamente focalizada), da capacidade da retina em detectar e processar os estímulos visuais, gerando sinais neurais, e da interpretação desses sinais pelas vias visuais superiores.

Em termos quantitativos e mensuráveis, a acuidade visual se refere à capacidade do sujeito em detectar, separar ou discriminar um objeto no espaço. Estas capacidades correspondem, respectivamente, ao menor objeto detectável (acuidade de detecção), à menor distância entre dois objetos que permita detectálos como dois (acuidade de separação ou de resolução) e ao menor objeto discriminável ou reconhecido (acuidade de discriminação ou de reconhecimento) (CARMONA et al, 2006). De acordo com o autor:

A acuidade também pode ser entendida como sendo uma característica do olho de reconhecer dois pontos muito próximos ou como a clareza ou nitidez da visão ocular ou a habilidade dos olhos de enxergar detalhes finos. A acuidade depende das funções da retina, da transmissão nervosa e da habilidade interpretativa do encéfalo. Em termos simples, a acuidade é a clareza de visão dos detalhes e se divide em qualitativa (capacidade de ver objetos perto um do outro de maneira distinta) e quantitativa (reciprocidade do valor angular de separação entre dois objetos vizinhos que os olhos podem ver separados) (CARMONA et al, 2006).

O estímulo de percepção visual do olho humano é não linear. Devido a isso foi estabelecida a Lei de Weber-Fechner, que se baseia em um modelo logarítmico da percepção subjetiva de estímulos, para os quais somente a diferença de brilho é perceptível (STOLFI, 2008).

Em relação ao campo de visão, o ser humano enxerga objetos em um campo visual pré-definido, que corresponde à área total ou espaço visível na visão periférica com o olho direcionado para frente. A extensão média é de 
aproximadamente 65 acima, 75 abaixo, 60ำ para dentro e 95 para fora. Já 0 campo visual humano binocular é de aproximadamente 124․ Campos visuais podem ser medidos pela perimetria e podem ser análogos aos eixos visuais utilizados em mapeamento.

Baseado nisso, Celestino (2017) determinou que a acuidade visual humana é proporcional ao logaritmo da intensidade do estímulo e este estímulo deve crescer exponencialmente para que a vista humana consiga diferenciá-lo conforme aumenta a distância em relação ao objeto observado. Alguns de nossos sentidos operam de maneira logarítmica, o que torna o uso de escalas logarítmicas apropriado para determinar distâncias.

De acordo com os resultados apresentados pela autora, a partir de uma distância de 7100 m, a considerar somente os cálculos lineares, a projeção da visão humana da torre de $24 \mathrm{~m}$ (ao se utilizar um anteparo) é menor do que o valor determinado de 0,01774 m perceptível pela acuidade visual humana. Considerando que o estímulo deve ser exponencial para o objeto poder ser perceptível pelo observador humano conforme se distancia do mesmo, a autora calculou que, em uma escala logarítmica, essa projeção da visão humana na torre de $24 \mathrm{~m}$, a partir de uma distância de 6300 m, já não pode mais ser percebida, pois a visão perde nitidez e a torre de $24 \mathrm{~m}$ passa a não ser mais percebida pelo observador.

\section{Área de estudo}

A pesquisa abrangeu uma área física de $741 \mathrm{Km}^{2}$, definida a partir de um raio de referência de $10 \mathrm{Km}$ no entorno das quatro $\mathrm{PCHs}$ do Rio Pelotinhas (Santo Cristo, Penteado, Rincão e Coxilha Rica) consideradas no estudo, envolvendo parte dos territórios de Capão Alto e Lages, municípios do Estado de Santa Catarina/Brasil. (Ver figura 01). Pelo menos 50\% da área estudada é composta pela região da Coxilha Rica, uma importante região do município de Lages, que ocupa pouco mais de $800 \mathrm{~km}^{2}$ de área e destaca-se por sua beleza natural e por seu rico patrimônio arquitetônico.

Através da Coxilha Rica atravessavam importantes rotas de transporte terrestre, denominadas "Caminhos das Tropas", construídas pela Coroa Portuguesa nos séculos XVIII e XIX com objetivos de povoar o interior do Brasil Colônia e expandir as fronteiras do seu território, prevenir os ataques e incursões espanholas, promover a comunicação e integração terrestre entre as Capitanias e o interior, 
estabelecendo um caminho fixo e seguro para o transporte das tropas e mercadorias que abasteciam o mercado interno (ABATI et al, 2010).

De acordo com Herberts (2009), o principal motivo da criação desses corredores era facilitar o transporte e evitar a dispersão dos animais. A maioria era composta por muares, por serem mais resistentes que os cavalos para o transporte de cargas pesadas em longas distâncias e em locais de difícil acesso. O mercado interno necessitava de abastecimento de mercadorias e as Minas Gerais necessitavam de animais fortes e resistentes para o transporte do ouro encontrado.

Figura 01 - Área de estudo.

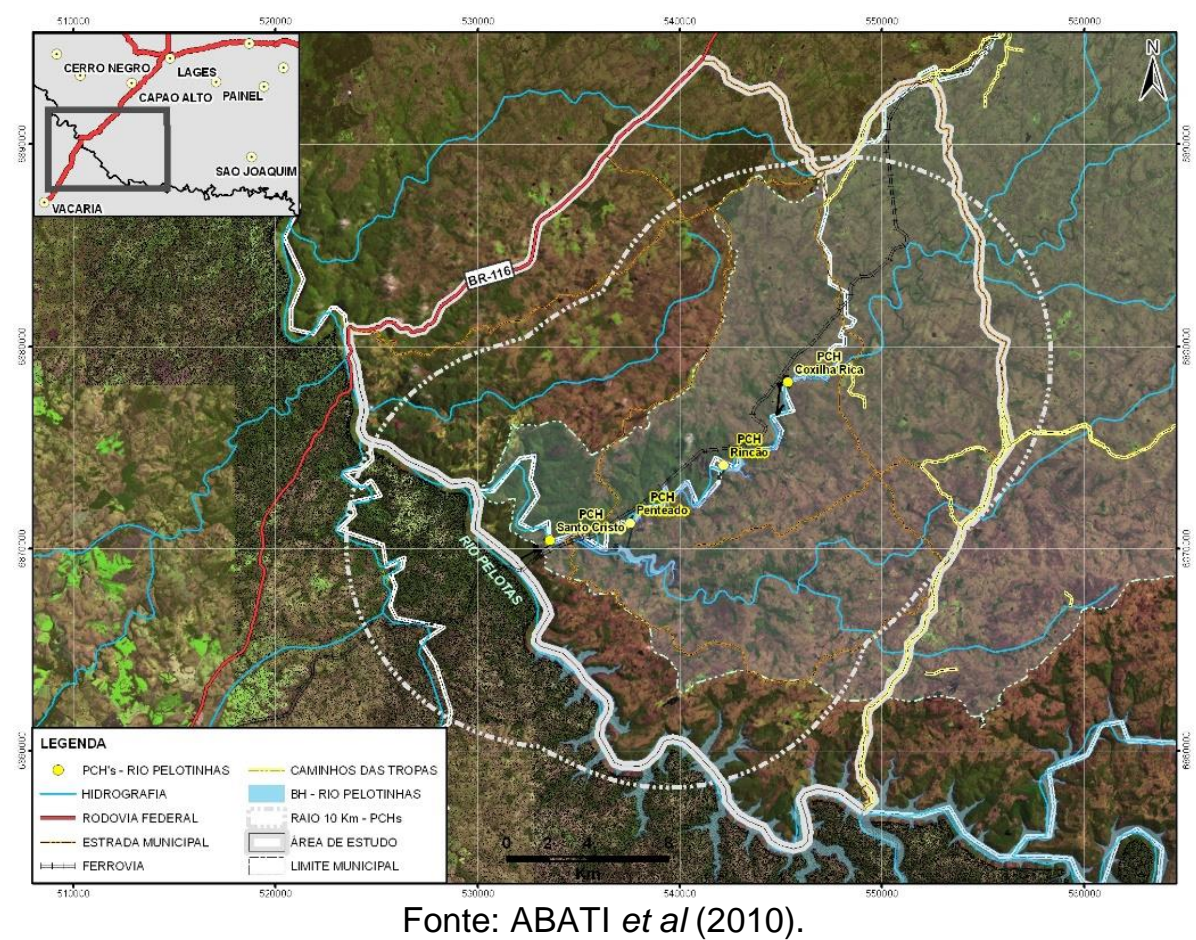

Nos séculos seguintes, durante o ciclo do café também foram utilizadas as tropas de muares nos caminhos e, com o tempo, foram criadas várias ramificações destes. O percurso em geral era determinado pelas condições do terreno, pela marcha dos animais e pelos locais de pastagem, água e pouso. Ao longo do caminho foram criadas estações para esses pousos, determinando o povoamento destes locais, seja através da construção de fazendas ou de estabelecimentos comerciais. Os pousos duravam às vezes muitos meses e a tropa necessitava engordar e se restabelecer fisicamente, pois ficavam muito debilitadas devido à distância e às dificuldades da viagem. Em contrapartida, os tropeiros se obrigavam a esperar a baixa dos rios para realizar a travessia dos animais com maior segurança (HERBERTS, 2009). 
Para a construção dos primeiros caminhos e fazendas, geralmente a mão de obra utilizada era escrava e patrocinada pelos donos de terras. O solo era pedregoso, na maior parte formado por pedras de basalto. Então, para maior segurança e menor impacto na viagem das tropas, os caminhos foram despedrados e o basalto retirado do solo serviu como matéria-prima para a construção dos corredores de taipa, que se constituíam, basicamente, em muros de pedra intatos, encaixados hermeticamente sem a necessidade de qualquer tipo de argamassa (ABATI et al, 2010). Ver Figura 02.

Figura 02 - Corredores de taipas.

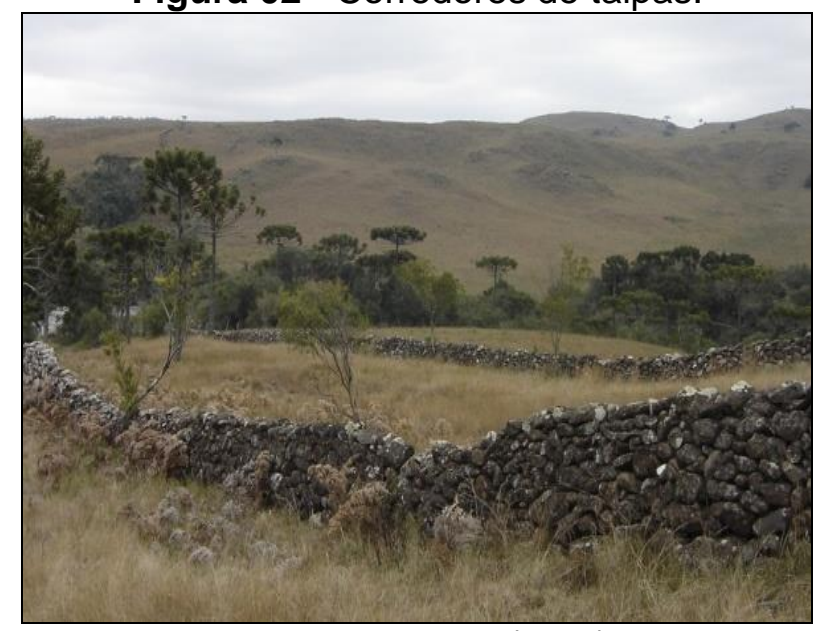

Fonte: ABATI et al (2010).

Na Coxilha Rica ainda se encontram preservados boa parte desses caminhos erguidos em taipa, bem como muitas fazendas centenárias, que acabaram por criar um conjunto de remanescentes histórico, cultural, arquitetônico e paisagístico, inexistentes em outras regiões do Brasil por onde o Tropeirismo se estendeu. Em muitos trechos desses caminhos e fazendas, o estado de conservação ainda é grande e merecem ser preservados.

$\mathrm{Na}$ área de estudo, dentre as muitas fazendas históricas e não históricas, e dezenas de quilômetros de caminhos das tropas identificados, foram caracterizadas 10 fazendas com elevado grau de preservação ou de relevância histórica e cultural, e dois trechos com um total de $6,9 \mathrm{Km}$ dos caminhos das tropas com alto grau de preservação e sem intervenção construtiva recente. Essas 10 fazendas e os 6,9 Km de trechos dos caminhos das tropas foram os objetos de estudo considerados para a geração das poligonais de visibilidade apresentadas neste trabalho. 


\section{Procedimentos Metodológicos}

Neste capítulo estão descritos os procedimentos metodológicos utilizados na pesquisa, levando em consideração que, em lugares turísticos, onde a paisagem faz parte do contexto do turismo, estimar a percepção ou o olhar subjetivo do observador como um eixo (vetor ou objeto de forma objetiva) é importante. Esse olhar é inserido dentro do SIG como um nível, ou seja, uma premissa ou condição a ser respeitada e preservada ao gerar mapas. Os procedimentos metodológicos estão sintetizados no fluxograma da Figura 03.

Figura 03 - Fluxograma sintetizado dos procedimentos metodológicos.

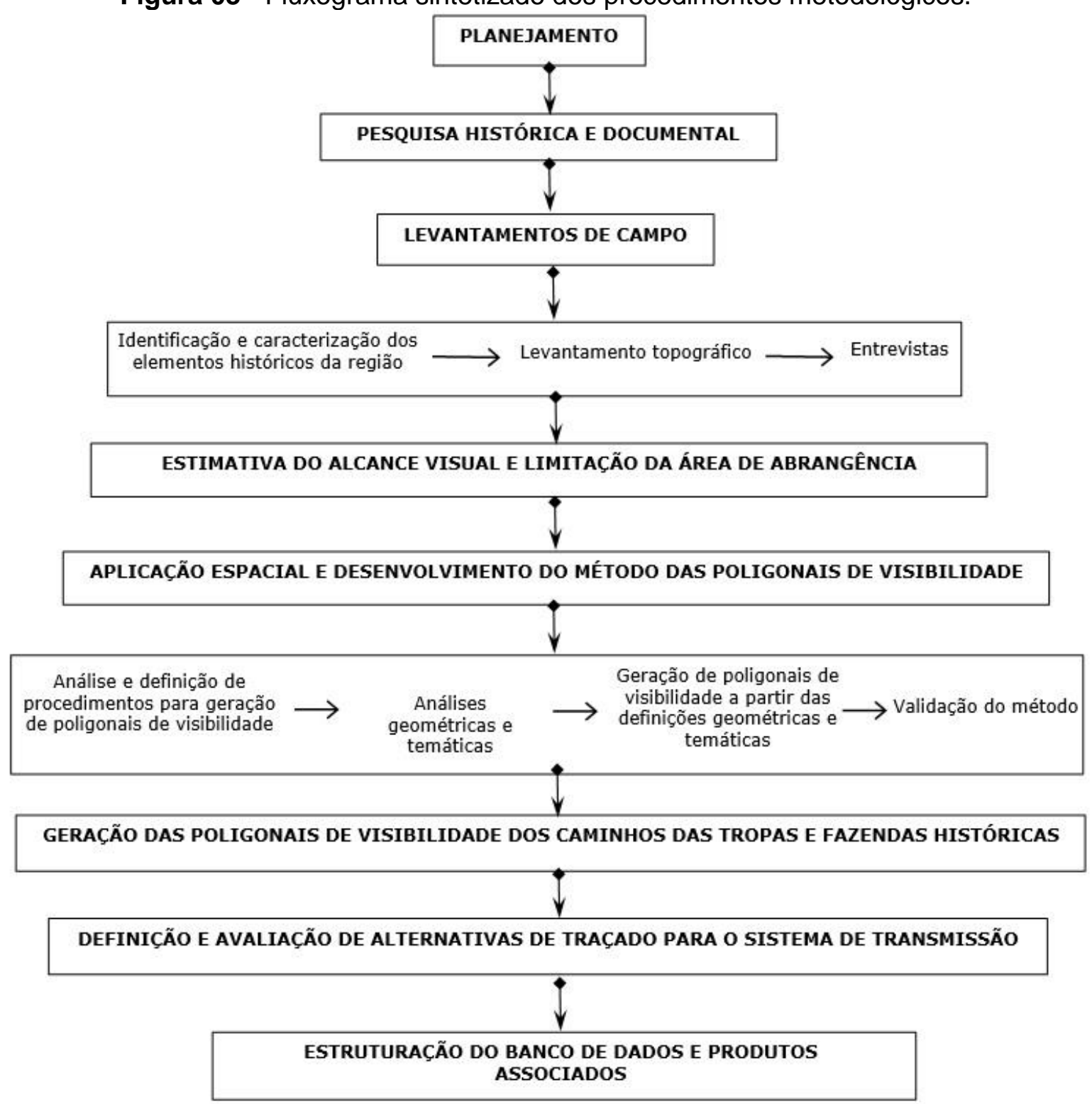

Org.: Elaborado pelos autores.

Primeiramente foi realizada pesquisa bibliográfica e levantamentos in loco para identificar e caracterizar elementos históricos. Foram obtidos títulos de imóveis 
(transcrições e matrículas), realizados registros fotográficos e mapeamentos expeditos de acessos, fazendas, corredores de taipa, entre outros. Após isso, foram realizadas entrevistas com proprietários de 10 fazendas históricas para preenchimento da ficha padrão do IPHAN, bem como foi realizado cadastro de elementos históricos em cada fazenda. Uma rede geodésica foi materializada para apoiar os levantamentos topográficos e cada marco implantado recebeu uma codificação inequívoca e uma monografia. As coordenadas foram obtidas por sistema orbital Global Navigation Satellite System (GNSS), pelo método relativo estático e georreferenciadas ao Sistema Geodésico Brasileiro (SGB). Para produzir os mapas de implantação das fazendas históricas na escala 1:2000 foram realizados levantamentos topográficos convencionais, e a elaboração das plantas baixas das casas principais de cada fazenda foram executadas com emprego de trenas analógicas e laser e máquina fotográfica, de acordo com as NBR 6409:1997, NBR 8402:1994 e NBR 8403:1984. Foi definida como raio de abrangência das poligonais de visibilidade a distância máxima de 8000 m, distância considerada necessária para que um observador não mais percebesse visualmente o objeto definido no horizonte (torre de $24 \mathrm{~m}$ ), conforme a definição da acuidade visual humana apresentada em Celestino (2017). Para organizar as bases cartográficas, as fazendas históricas obtiveram representação pontual, os corredores de taipas representação linear, e o modelo digital de elevação (MDE) utilizado, advindo da Advanced Spaceborne Thermal Emission and Reflection Radiometer - Global Digital Elevation Model (ASTER GDEM), obteve representação de tesselação (matriz). Considerando as dimensões variáveis dos objetos de análise e o objetivo de identificar apenas as áreas de visibilidade do entorno das sedes das fazendas históricas e dos eixos dos corredores de taipa, foram definidas as seguintes representações:

- Sede da fazenda: área no raio mínimo de $250 \mathrm{~m}$ a partir do seu centro, equivalente a $200.000 \mathrm{~m}^{2}$, representada espacialmente por uma malha de 257 pontos com pixel de $30 \mathrm{~m}$.

- Caminhos das tropas: área entre os muros de taipa ao longo de toda sua extensão, representados espacialmente por uma malha linear variável de pontos, de modo a abranger uma largura mínima de $30 \mathrm{~m}$.

- Ponto de referência: ponto representativo do objeto, em posição de destaque, em elevação, com boa visão do entorno e dentro dos limites do objeto (sede da fazenda ou caminhos das tropas). 
- Poligonal de visibilidade do ponto de referência: área observada no raio de $360^{\circ}$ a partir do ponto de referência. É a poligonal de visibilidade resultante do ponto de referência utilizado no procedimento de validação do método.

- Poligonal de visibilidade da Sede da fazenda: área observada no raio de $360^{\circ}$ a partir da Sede da fazenda ou toda superfície observada por um observador posicionado em qualquer um dos 257 pontos que a representam.

- Poligonal de visibilidade dos caminhos das tropas: área observada no raio de $360^{\circ}$ a partir do eixo de um determinado trecho do caminho das tropas ou toda superfície observada por um observador posicionado em qualquer ponto da malha linear de pontos que o representam.

Para gerar as poligonais de visibilidade brutas foi utilizado o MDE, e o ponto de referência foi criteriosamente definido: posição de destaque, em elevação, próximo da sede da fazenda histórica, com boa visão do entorno e representativo de cada fazenda. O mesmo critério foi aplicado para a definição das linhas de referência para os caminhos das tropas, onde em um determinado trecho do caminho foi realizada simulação de um observador caminhando sobre o corredor de taipas, o que resultou em uma área de visibilidade diferente para cada ponto percorrido. No software ArcGIS foram utilizadas as funções do 3D Analyst, para gerar as 14 poligonais de visibilidade individuais brutas (10 a partir de fazendas históricas e quatro a partir de trechos dos corredores de tropas). As poligonais "brutas" foram classificadas de acordo com a frequência que determinada porção da superfície topográfica era visível por uma determinada quantidade ou intervalo de pontos de observação. Neste estudo foram definidos três intervalos de classe para as áreas de visibilidade:

- Baixa Visibilidade (1): corresponde às áreas de visibilidade observadas por, no mínimo, um ponto de referência e, no máximo, por 1/3 do total de pontos.

- Média Visibilidade (2): corresponde às áreas de visibilidade observadas por, no mínimo, 1/3 dos pontos e por, no máximo, 2/3 do total de pontos.

- Alta Visibilidade (3): corresponde às áreas de visibilidade observadas por, no mínimo, 2/3 dos pontos e, no máximo, a totalidade dos pontos.

Para as poligonais de visibilidade das sedes das fazendas, em função da malha de 257 pontos de referência estabelecida, as novas classes foram reformuladas para: Value $=1$ (intervalo de 1 a 85 ); Value $=2$ (intervalo de 86 a 170); 
Value $=3$ (intervalo de 171 a 257); Value $=0$ (nulo). Nas poligonais de visibilidade dos caminhos das tropas foram definidos os seguintes intervalos de valores: Value = 1 (intervalo de 1 a 33); Value = 2 (intervalo de 34 a 66); Value = 3 (intervalo de 67 a 99); Value = 0 (nulo).

Considerando que cada célula do MDE representa uma área de $900 \mathrm{~m}^{2} \mathrm{na}$ superfície topográfica (pixel de $30 \mathrm{~m}$ ), cada área de célula foi multiplicada pela quantidade de ocorrências para obter a área total de visibilidade. A análise resultou em um novo raster que conteve as áreas de visibilidade da malha de pontos. $\mathrm{Na}$ sequência, foi aplicado um gradiente de cores para representar espacialmente os valores visíveis absolutos de cada poligonal de visibilidade. Assim foi definido 0 gradiente de cores, sendo que para value $=0$ foi definida cor nula e o valor de 254 foi definido para a quantidade máxima de pontos que podem observar uma determinada quantidade de células ao mesmo tempo. Após a geração de cada poligonal de visibilidade classificada de forma individual, as mesmas foram sobrepostas, resultando em uma nova poligonal com a área total de visibilidade observada a partir de todos os Elementos Históricos (EH) estudados de forma simultânea, sem considerar os pesos atribuídos. Para realizar a nova classificação, foi considerada a área total observada a partir dos $\mathrm{EH}$ em relação à visibilidade (independente do grau atribuído: baixo, médio ou alto). Desta forma, foram identificados quantos e quais elementos observam simultaneamente uma mesma porção da superfície topográfica, mesmo que em pouca quantidade. A priori, foi verificado que, apesar de terem sido utilizados 14 Elementos Históricos (EH) no estudo, somente foi possível observar, no máximo, oito deles a partir de um outro EH. Devido a isso, foram também definidos novos intervalos de valores:

- Value =1 (1 EH observado a partir de outro EH)

- Value = 2 (2 EH observados a partir de outro $\mathrm{EH}$ )

- Value = 3 (3 EH observados a partir de outro $\mathrm{EH}$ )

- Value = 4 (4 EH observados a partir de outro $\mathrm{EH}$ )

- Value = 5 (5 EH observados a partir de outro EH)

- Value $=6$ (6 EH observados a partir de outro $\mathrm{EH})$

- Value $=7$ (7 EH observados a partir de outro $\mathrm{EH})$

- Value $=8$ (8 EH observados a partir de outro $\mathrm{EH})$

Para avaliar a qualidade, foram utilizados como referência três fazendas históricas e três trechos dos caminhos das tropas. Para a avaliação geométrica, 
foram realizados levantamentos topográficos nos pontos de referência e na posterior fixação de balizas e bandeiras identificadas a cada $45^{\circ}$ em um raio de 15 metros, perfazendo um círculo de $360^{\circ}$. A referência utilizada para amarrar o levantamento foi o norte da quadrícula da projeção Universal Transversa de Mercator (UTM). Após o levantamento das coordenadas de cada bandeira, para realizar a avaliação qualitativa foi instalada nos mesmos pontos de referência uma máquina fotográfica para a tomada de fotografias e vídeos no mesmo raio de $360^{\circ} \mathrm{com}$ a devida identificação das balizas e bandeiras a cada $45^{\circ}$. Para definir e avaliar os corredores de estudo para o sistema de transmissão, foram estipuladas três alternativas de corredores de estudo para a interligação entre as $\mathrm{PCH}$ e três alternativas de corredores de estudo para a conexão ao SIN. Os corredores de estudo do sistema de transmissão foram analisados isoladamente a partir de cada elemento histórico e posteriormente em conjunto, possibilitando uma avaliação de forma integrada de todo o ambiente paisagístico da região.

\section{Resultados e Análises}

Neste capítulo serão apresentados os resultados obtidos na pesquisa, bem como as análises realizadas a partir dos resultados obtidos.

Foram gerados, como resultados, quatro mapas de poligonais de visibilidade a partir de cada um dos cinco pontos de referência definidos no procedimento de análise e validação do método. Em cada mapa estão representadas as bandeiras de sinalização, os azimutes a cada $45^{\circ}$ e os raios de distância de $8 \mathrm{~km}$ (ver exemplo na Figura 04), que apresenta a poligonal de visibilidade do ponto de referência a partir da Fazenda Santa Cecília e na Figura 05, que apresenta a poligonal de visibilidade do ponto de referência dos caminhos das tropas referente ao trecho CT-T1A.

Para cada ponto de referência mapeado foram produzidas sequências de oito fotografias, por setor de $45^{\circ}$, apresentando a visão em $360^{\circ}$ do observador posicionado no ponto de referência. Ver exemplo de fotografia na Figura 06, que apresenta a visão do observador a partir do Setor $1\left(0^{\circ}\right.$ a $\left.45^{\circ}\right)$ na Fazenda Santa Cecília e na Figura 07 que apresenta a visão do observador a partir do Setor 1 do trecho CT-T1A. 
Figura 04 - Poligonal de visibilidade a partir da Fazenda Santa Cecília (Referência).

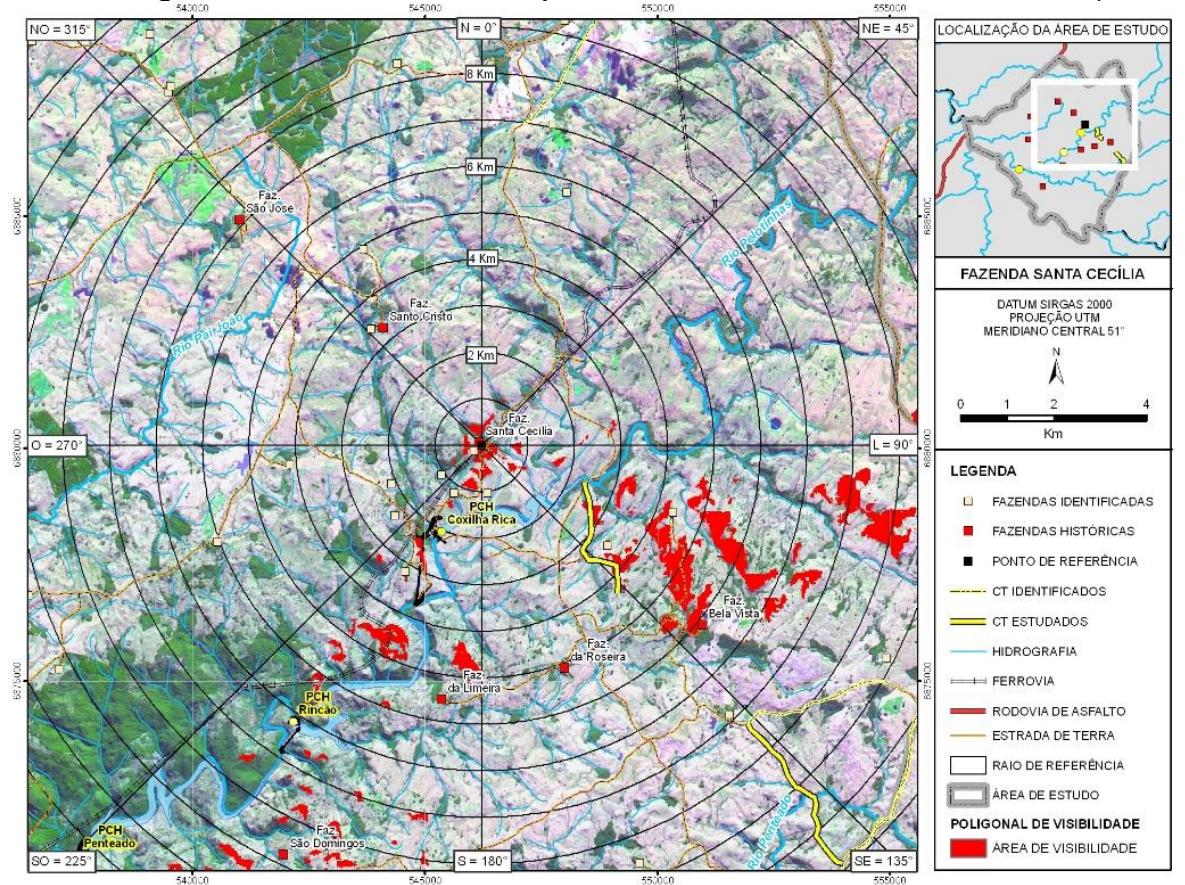

Fonte: ABATI et al (2010).

Figura 05 - Poligonal de visibilidade a partir do trecho CT-T1A (Referência).

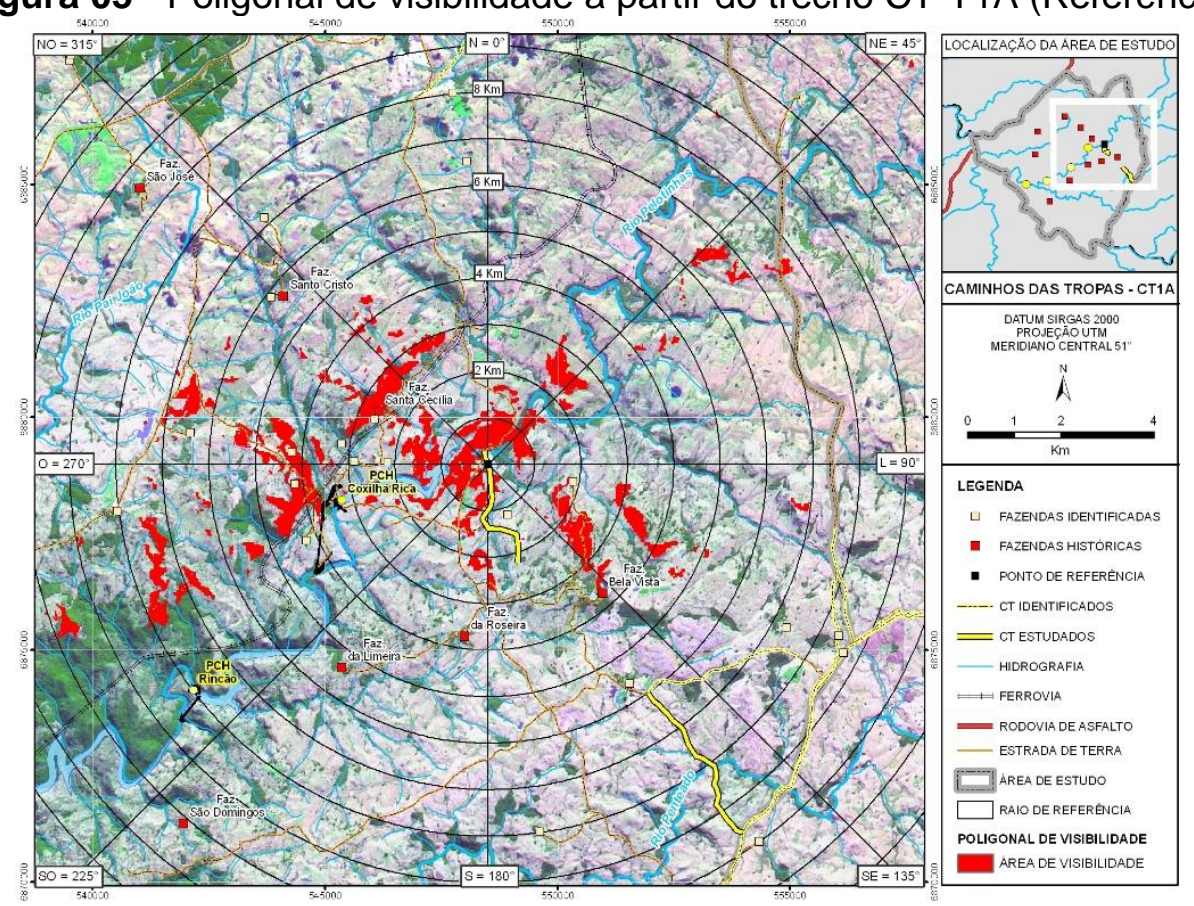

Fonte: ABATI et al (2010). 
Figura 06 - Visão do observador a partir do Setor 1 - Fazenda Santa Cecília.

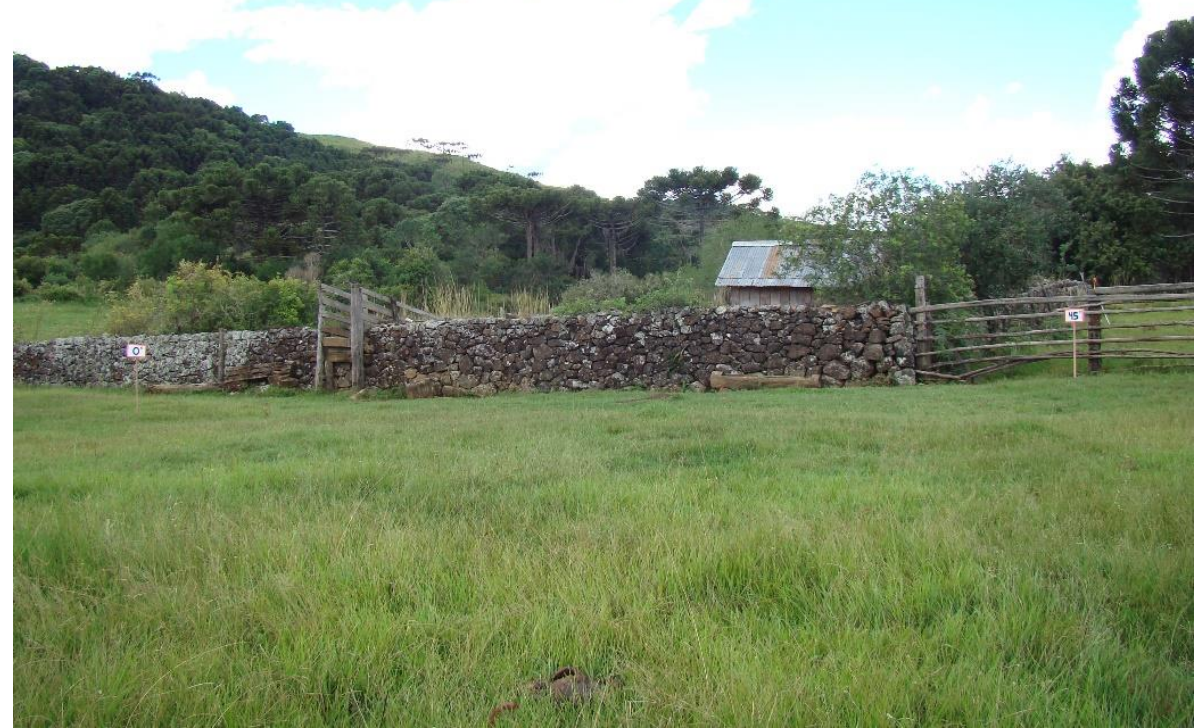

Fonte: ABATI et al (2010).

Figura 07 - Visão do observador a partir do Setor 1 - Trecho CT-T1A.

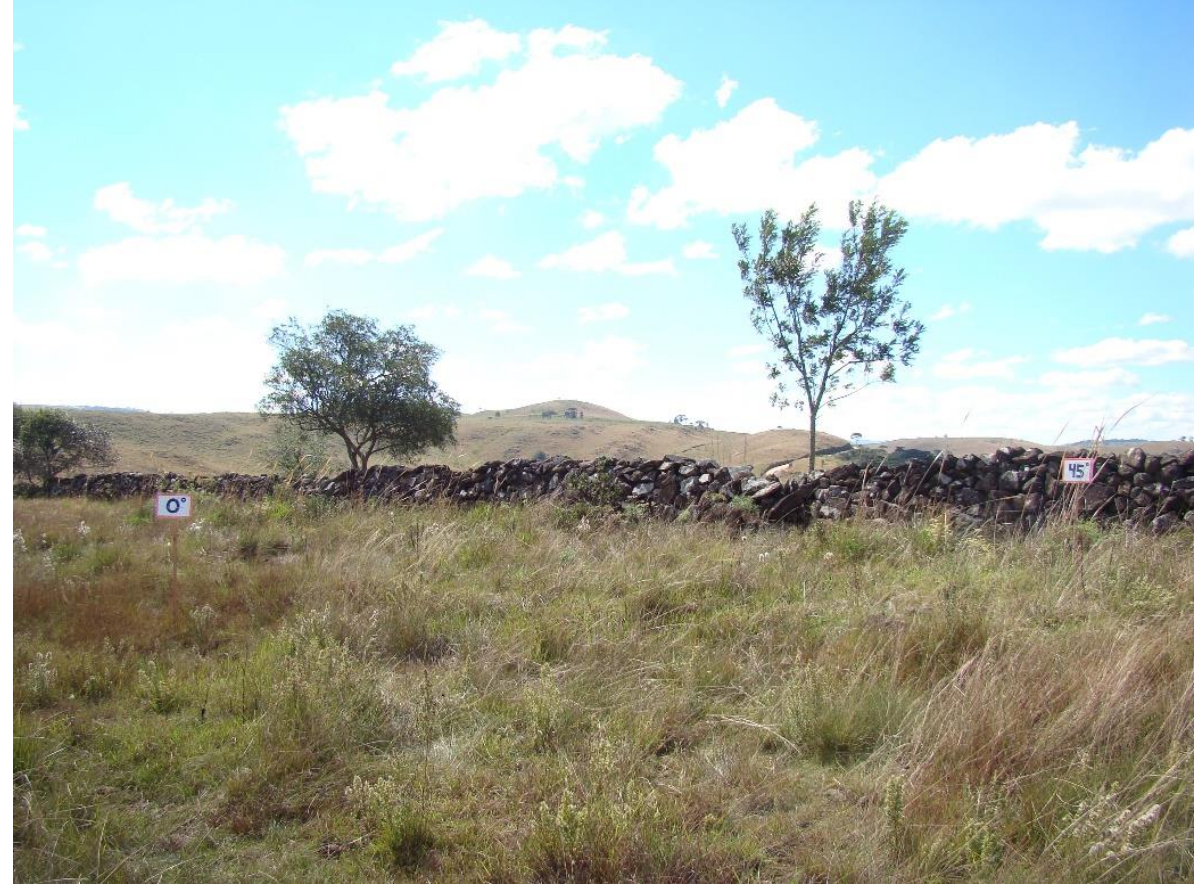

Fonte: ABATI et al (2010).

Nos mapas, conforme apresentado nas Figuras 04 e 05, as "manchas vermelhas" sobre a superfície do terreno são as poligonais de visibilidade brutas geradas a partir dos pontos de referência e correspondem às porções da superfície 
visualizadas pelo observador posicionado naquele local. Quando comparadas com as filmagens e fotografias de campo durante a avaliação da qualidade (Figuras 06 e 07), é possível analisar os resultados isoladamente em cada setor.

A análise visual dos resultados gerou uma concordância positiva das áreas de visibilidade identificadas, tanto pelas técnicas de geoprocessamento, quanto pelas fotografias e filmagens obtidas in loco. Contudo, foi observado também nas fotografias alguns elementos naturais ou artificiais não representados pelo ASTER GDEM e que acabaram interferindo na avaliação dos produtos. Esses elementos correspondem, principalmente, a algum tipo de vegetação existente no cume de um morro ou a uma pequena elevação no entorno dos pontos de referência e que significaram um obstáculo para a visão do horizonte.

Já os resultados verificados nas poligonais de visibilidade geradas nas análises de geoprocessamento, indicaram visibilidade além daqueles obstáculos, uma vez que não são representados pelo ASTER GDEM. Desta forma foi possível identificar algumas limitações do método inerentes à resolução e à generalização do modelo de elevação utilizado (ASTER GDEM).

Outra limitação corresponde às condições de visibilidade do observador em relação a possíveis obstáculos naturais ou artificiais, como uma mata, um morro, um reflorestamento ou uma edificação posicionada no eixo de visão do observador, impedindo sua visão além daquele obstáculo. Apesar das limitações do método, os resultados, avaliados visualmente, foram satisfatórios e garantiram a qualidade dos produtos gerados, possibilitando o emprego da metodologia para a geração das poligonais de visibilidade dos caminhos das tropas e das sedes das fazendas históricas. Sob o ponto de vista da preservação do ambiente cênico, a limitação do método, inerente à identificação de obstáculos pequenos, garante que a poligonal gerada apresenta visibilidade além do observado em campo.

Em relação às fazendas, foram gerados como resultados 10 mapas de poligonais de visibilidade das 10 fazendas históricas definidas: Santa Cecília, São Domingos, Santo Cristo I, São José, Pai João, Chapada, Bela Vista, Roseira, Limeira e Paiquerê. Nos mapas foram representadas as áreas de visibilidade, os raios de abrangência da poligonal de visibilidade, os azimutes a cada $45^{\circ}$ e suas respectivas bandeiras de sinalização em relação ao ponto central da fazenda. Ver exemplo na Figura 08 que apresenta a poligonal de visibilidade bruta da sede da fazenda Santa Cecília. 
Figura 08 - Poligonal de visibilidade a partir da fazenda Santa Cecília (Bruta).

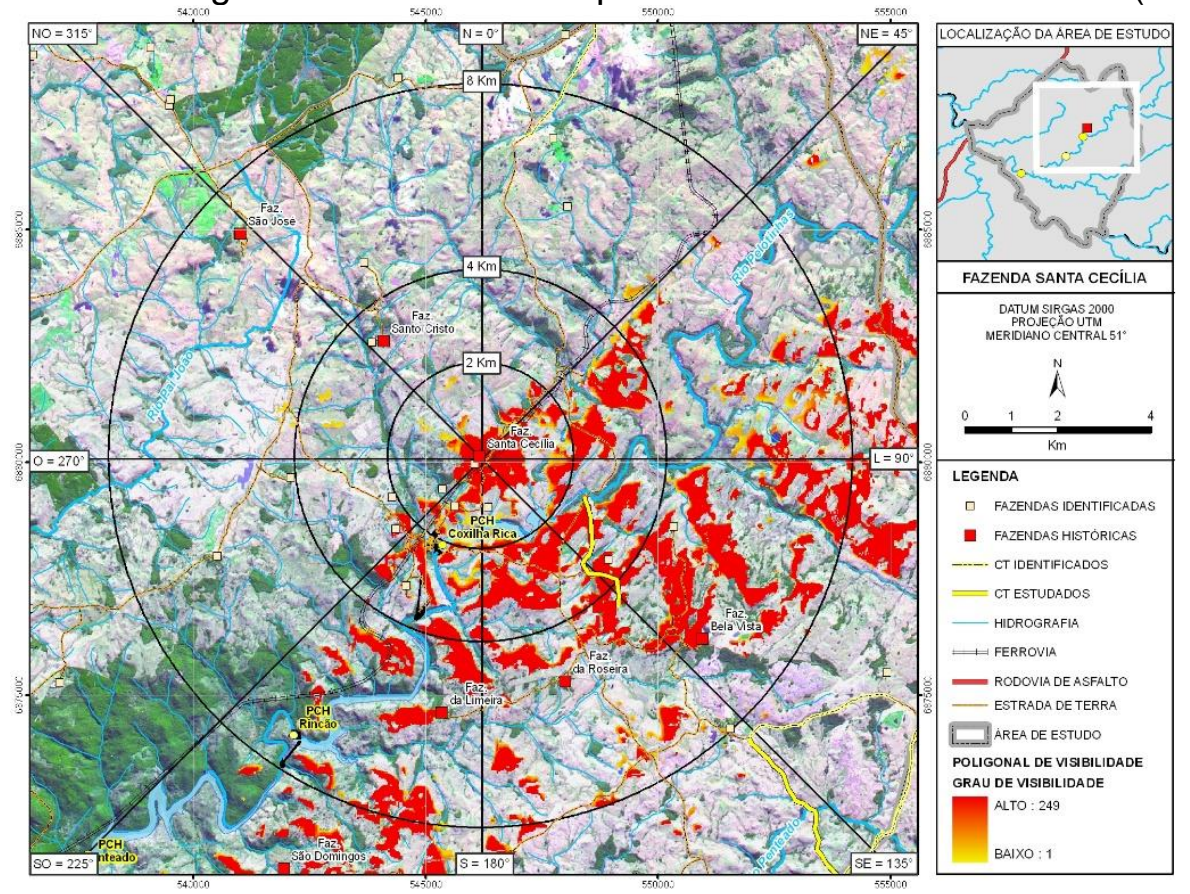

Fonte: ABATI et al (2010).

Em relação aos corredores de tropas, foram gerados como resultados quatro mapas de poligonais de visibilidade de três segmentos dos caminhos das tropas. Nos mapas foram representadas as áreas de visibilidade e os raios de abrangência da poligonal de visibilidade em relação ao eixo central do corredor de taipa (ver exemplo na Figura 09), que apresenta o mapa da poligonal de visibilidade bruta do segmento CT-T1A referente ao trecho do rio Pelotinhas.

Figura 09 - Poligonal de visibilidade a partir do segmento CT-T1A (Bruta).

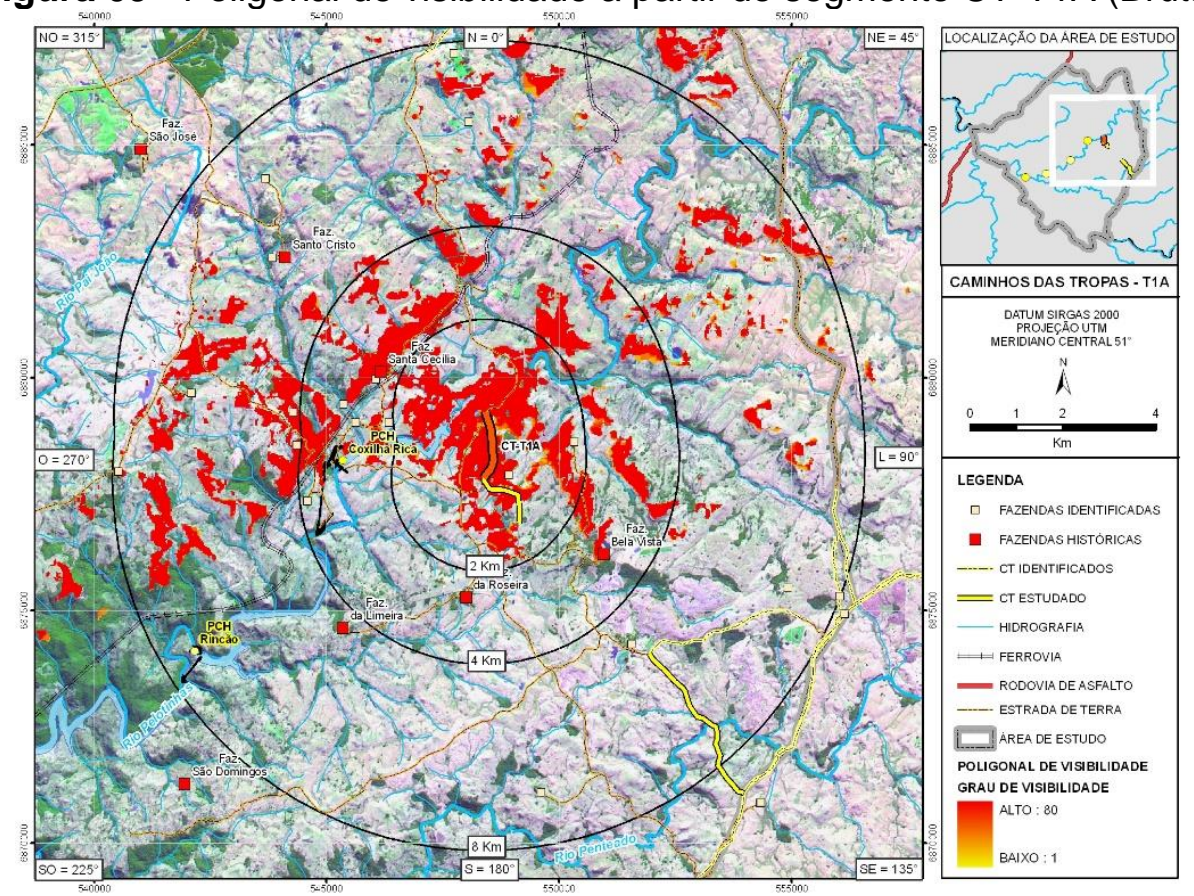

Fonte: ABATI et al (2010). 
As áreas de visibilidade das fazendas e corredores estão representadas pelo gradiente de cores "Stretched" que indica a variação da quantidade de pontos que podem ser observados em determinada porção da superfície, ou seja, os valores absolutos "brutos" de cada poligonal de visibilidade.

Após a geração das poligonais de visibilidade "brutas" foi possível gerar os mapas das poligonais de visibilidade das 10 fazendas históricas classificadas quanto ao grau de visibilidade e limitadas no raio de $8 \mathrm{Km}$ de abrangência. No mapa da Figura 10 (fazenda Santa Cecília), por exemplo, é possível observar as áreas de visibilidade representadas pelas três classes previamente definidas: baixa, média e alta.

Figura 10 - Poligonal de visibilidade classificada a partir da fazenda Santa Cecília.

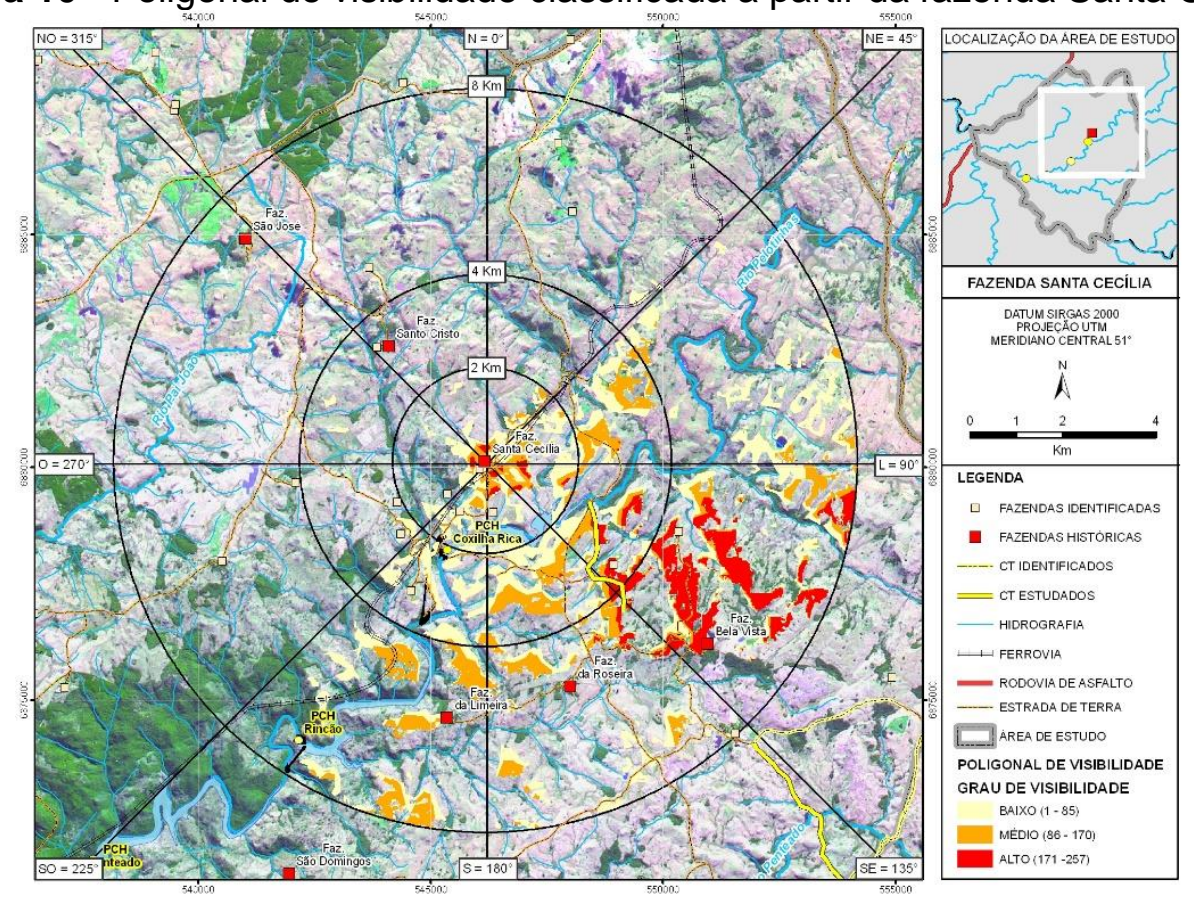

Fonte: ABATI et al (2010).

A classificação por grau de visibilidade permitiu identificar as áreas de maior visibilidade e, consequentemente, aquelas que merecem maior atenção nas análises de intervenção na paisagem. Foram tecidos questionamentos importantes para realizar a análise de intervenção na paisagem, por exemplo, "é preferível que uma torre do sistema de transmissão esteja visível de uma distância pequena, porém a partir de poucos lugares?" ou "é preferível que a torre esteja visível de uma distância maior, porém a partir de muitos lugares?". Neste sentido, foi analisado cada caso em específico, pois quanto maior a distância entre o objeto e o observador, menor a resolução do objeto observado e o poder de visualização do observador. Esta relação de "distância versus grau de visibilidade" requereu análises específicas, 
sendo talvez a principal variável considerada nas tomadas de decisão para a inserção ou não do sistema de transmissão.

Para os caminhos das tropas (corredores de taipa), foram gerados mapas das poligonais de visibilidade dos segmentos dos caminhos das tropas classificadas quanto ao grau de visibilidade, de forma análoga ao das fazendas históricas. Ver Figura 11 que mostra o exemplo para o trecho CT-T1A.

Figura 11 - Poligonal de visibilidade classificada a partir do trecho CT-T1A.

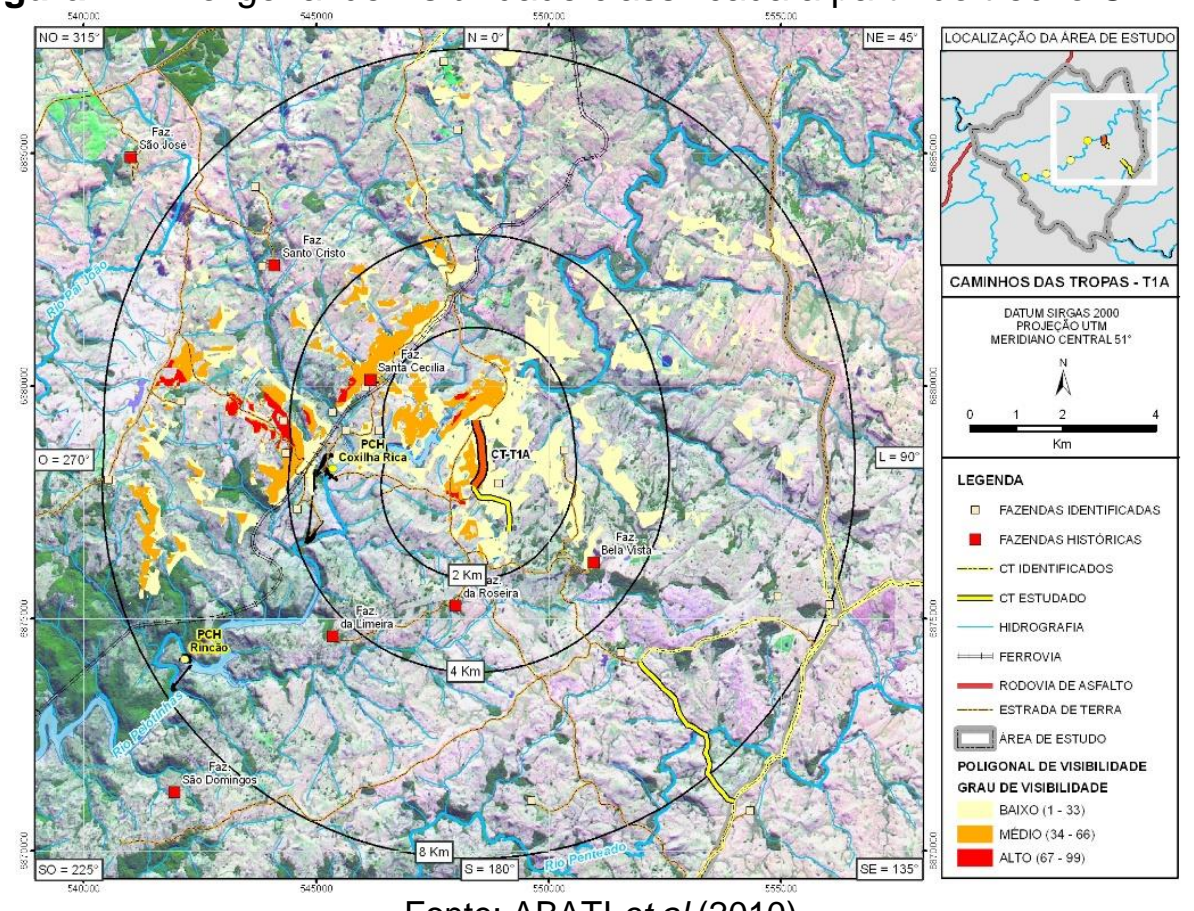

Fonte: ABATI et al (2010).

Os mapas específicos dos elementos históricos foram de fundamental importância na análise isolada. Neste sentido foi possível avaliar para cada fazenda histórica ou para cada segmento dos caminhos das tropas qual seria a melhor alternativa para o sistema de transmissão, bem como o potencial impacto visual a ser gerado.

O mapa da Figura 12 corresponde à poligonal de visibilidade (PV) total dos 14 elementos históricos $(\mathrm{EH})$ caracterizados. Neste mapa, para cada porção da superfície topográfica identificada como visível, é possível identificar a partir de quantos, e quais, EH podem observar aquela determinada parcela da superfície. A sobreposição de todas poligonais individuais possibilitou a classificação dos valores da PV total em oito classes. Isso significa que cada porção da superfície visível pode ser observada a partir de um e, no máximo, de oito HE.

Através da análise integrada foi possível projetar e avaliar alternativas para os corredores de estudo do futuro sistema de transmissão das PCHs do rio Pelotinhas, 
visando minimizar o impacto visual sobre o ambiente cênico da paisagem. No mapa da Figura 12 pode ser observado que os corredores ilustrados na cor branca correspondem às alternativas de estudo sugeridas para a interligação entre as quatro $\mathrm{PCH}$ e os corredores ilustrados na cor azul correspondem às alternativas de estudo sugeridas para a conexão ao SIN.

Figura 12 - Alternativas de estudo para a interligação entre as PCHs.

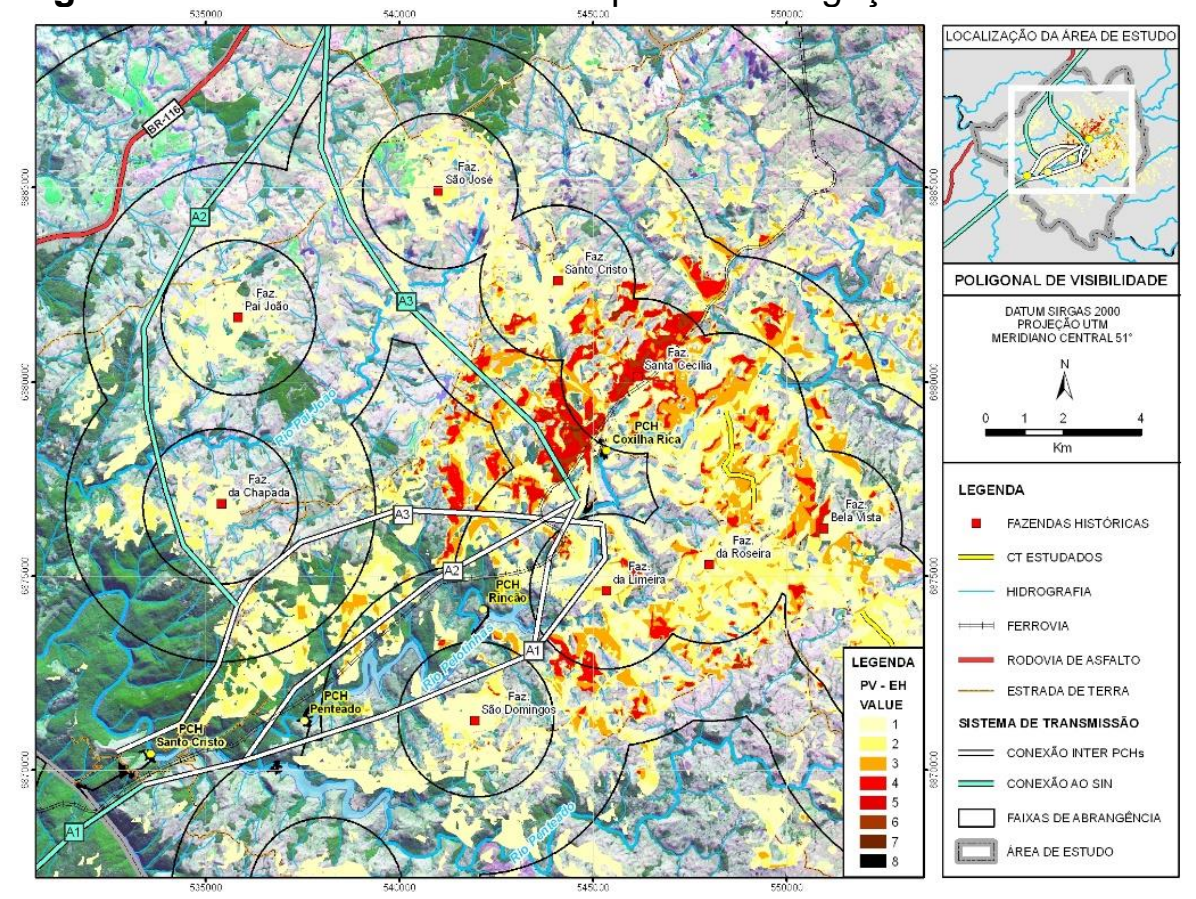

Fonte: ABATI et al (2010).

Com relação ao sistema de interligação das $\mathrm{PCHs}$, as três alternativas propostas ( $A 1, A 2$ e $A 3$ ), em branco na Figura 12, apresentaram algum tipo de interferência visual quando analisadas sobre a PV total dos HE. Quando analisadas isoladamente com a PV individual de cada HE, entretanto, foi possível verificar que sempre existia uma alternativa que não oferecia impacto visual.

As alternativas apresentadas neste trabalho foram consideradas na época do estudo como viáveis para a implantação do sistema de transmissão. Algumas alternativas apresentaram impacto visual maior ou menor em relação a outras, mas o resultado mais significativo é que, independente das alternativas projetadas, as áreas visíveis, assim como as áreas não visíveis, foram mapeadas e inseridas em uma base cartográfica, constituindo um importante banco de dados para auxiliar no suporte e na tomada de decisão nas análises de intervenção na paisagem por parte do IPHAN. 


\section{Considerações finais}

Considera-se que o objetivo principal deste estudo tenha sido atingido, pois foi demostrado na narrativa todo o método utilizado, embasamento teórico de suporte, bem como a avaliação da qualidade realizada, o que garante a confiabilidade do trabalho. O método se torna relevante na medida em que apresenta uma definição de distância limite para gerar as análises e os produtos cartográficos, utilizando a acuidade visual humana como referência.

Com a obtenção das poligonais de visibilidade geradas a partir de cada fazenda histórica ou de cada segmento dos corredores de taipas, foi possível, através de análises espaciais, realizar o cruzamento de níveis de informação, classificar e definir o grau de visibilidade da poligonal total, permitindo realizar a gestão da paisagem da Coxilha Rica.

Considera-se, ainda, que o objetivo específico de aplicar o estudo e avaliar alternativas de corredores para inserção de um futuro sistema de transmissão, com foco na minimização do impacto visual sobre o ambiente cênico da Coxilha Rica, também tenha sido atingido, sem onerar os empreendedores com custos financeiros relativos a recursos humanos e trabalhos de campo. Além disso, foi comprovado que o impacto visual na paisagem poderia ser minimizado a depender de onde fosse inserido o sistema de transmissão. Isso ocorreu devido à análise realizada a partir da visão do ponto de vista do observador simuladamente inserido nos elementos históricos da região.

Neste trabalho somente os elementos históricos caracterizados foram considerados para propor alternativas para o sistema de transmissão. Não foram considerados outros parâmetros de engenharia importantes, como: estudos ambientais de fauna e flora, geologia e tipos de estruturas metálicas.

O método e todos os produtos desenvolvidos na pesquisa foram fornecidos ao IPHAN, o que permitiu que o órgão dispusesse de subsídios para definir os melhores locais para realizar intervenções futuras na região, bem como gerar poligonais de visibilidade para diversas finalidades e identificar geograficamente as fazendas, caminhos das tropas e demais elementos históricos. Toda a produção foi considerada e constituída de um grande arcabouço para a tomada de decisão para a paisagem da Coxilha Rica.

Considerando todas as limitações de estudos de engenharia, ambiental e quanto à capacidade de suporte dos equipamentos dos possíveis pontos de 
conexão, o estudo aqui apresentado ainda alcançou seu objetivo, uma vez que, independente do destino final do sistema de transmissão, a metodologia desenvolvida permitiu verificar a possibilidade de projetar alternativas de traçado, eliminando ou minimizando ao máximo o impacto visual sobre o ambiente cênico da região, sem necessidade de intervir diretamente, o que em engenharia é muito válido. Ao final considera-se ainda que o método é universal e pode ser reproduzido em outras áreas distintas.

Importante ressaltar que, a partir do estudo desenvolvido e também movido por outras questões de natureza arqueológica que fogem à alçada desta pesquisa, foi permitido ao IPHAN tomar a decisão acerca do possível impacto que poderia existir na região, relativo à paisagem.

Das quatro PCHs envolvidas no Estudo, somente a $\mathrm{PCH}$ Santo Cristo de propriedade da Empresa CGT Eletrosul obteve LI do empreendimento, que como pode ser avaliado no estudo, através da apresentação da Figura 12, é a PCH situada mais distante das poligonais de visibilidade geradas, portanto era o projeto que apresentou menor impacto visual sobre o ambiente cênico e sobre a paisagem da região. Porém, até a publicação deste trabalho a mesma não havia sido construída devido a questões que tornaram o empreendimento menos atrativo economicamente e também devido à priorização de outros negócios por parte da Empresa CGT Eletrosul.

Do ponto de vista dos empreendedores, ficou comprovado, através desta pesquisa, que poderia haver uma minimização do impacto visual, caso o sistema tivesse sido construído por uma das alternativas propostas (linhas em branco e azul da Figura 12). Porém, os empreendedores concordam que problemas de ordem arqueológica, ambiental, político, de negócio e econômico, entre outros fatores associados, foram determinantes para que as $\mathrm{PCHs}$ não fossem construídas, mesmo com uma delas obtendo a licença de instalação (LI).

Desta forma, resta concluir que o ambiente cênico e paisagístico da região da Coxilha Rica continua preservado no tocante a empreendimentos de geração e transmissão de energia elétrica.

\section{Agradecimentos}

Agradecemos à empresa CGT Eletrosul pela disponibilização dos dados, materiais e demais recursos que permitiram realizar esta pesquisa. 


\section{REFERÊNCIAS}

ABATI, S., CELESTINO, V. S.; KUNZ, R. Complexo de PCH do rio pelotinhas - estudo de visibilidade: análise de intervenção na paisagem. Trabalho Técnico Eletrosul: Florianópolis, 2010.

AGENCIA NACIONAL DE ENERGIA ELÉTRICA (ANEEL). Atlas de energia elétrica do Brasil. ANEEL: Brasília, 3aㅡ edição, 2008.

CARMONA, F. M. M.; COSTA, M. F.; VENTURA, D. F.; SALOMÃO, S. R.; BARROS, P. S. M. Acuidade visual de resolução de grades pelo método dos potenciais visuais evocados de varredura: padronização da metodologia para uso em cães. Brazilian journal veterinary res. and animal science, São Paulo, v. 43, suplemento, p. 86 - 92, 2006.

CELESTINO, V. S.; KUNZ, R.; ABATI, S. Estudo de visibilidade análise de intervenção na paisagem estudo de caso na Coxilha Rica, Lages/SC. In: XXIV Congresso Brasileiro de Cartografia e II Congresso Brasileiro de Geoprocessamento, Aracaju/SE. Anais do XXIV Congresso Brasileiro de Cartografia, v. 1. 2010.

CELESTINO, V. S. Estimativa de alcance visual humano aplicado à preservação de ambientes cênicos. Revista de Geografia e Ordenamento do Território, Lisboa, Portugal, no11, p. $99-123,2017$.

GOLDEMBERG, J.; LUCON, O. Energia, Meio Ambiente e Desenvolvimento. Edusp: São Paulo, 2008.

HERBERTS, A. L. Arqueologia do Caminho das Tropas: Estudo das estruturas viárias remanescentes entre os rios Pelotas e Canoas, SC. 2006. Tese (Doutorado em História) Programa de Pós-Graduação em História (PPGH), Pontifícia Universidade Católica do Rio Grande do Sul (PUCRS), Porto Alegre, 2006.

MOURA, Ana Clara Mourão. Geoprocessamento da Gestão e Planejamento Urbano. Ed. da autora: Belo Horizonte, 2003.

SANTOS, M. A natureza do espaço: técnica e tempo; razão e emoção. Ed. Hucitec: São Paulo, 1997.

SILVA, A. F. Estratégias materiais e espacialidade: uma arqueologia da paisagem do Tropeiro nos Campos de Cima da Serra/RS. In: VI Congresso Internacional de Estudos Ibero-Americanos, 2006. EDIPUCRS: Porto Alegre, 2006.

STOLFI, G. Percepção Visual Humana. Televisão Digital, v. 4, p. 1 - 13, 2008.

UNESCO. Convenção do Patrimônio Mundial, 1999. IPHAN., 1999: Cartas Patrimoniais. Disponível em: http://unesdoc.unesco.org/images/0013/001333/133369por.pdf. Acesso em: 23 mar. 2009.

\section{NOTAS DE AUTOR}

Vivian da Silva Celestino Reginato - Concepção. Coleta de dados, Análise de dados, Elaboração do manuscrito, revisão e aprovação da versão final do trabalho.

Samuel Abati -. Concepção. Coleta de dados, Análise de dados, Elaboração do manuscrito, revisão e 
aprovação da versão final do trabalho.

\section{FINANCIAMENTO}

Não se aplica.

\section{CONSENTIMENTO DE USO DE IMAGEM}

Não se aplica.

APROVAÇÃO DE COMITÊ DE ÉTICA EM PESQUISA

Não se aplica.

\section{CONFLITO DE INTERESSES}

Não se aplica.

\section{LICENÇA DE USO}

Este artigo está licenciado sob a Licença Creative Commons CC-BY. Com essa licença você pode compartilhar, adaptar, criar para qualquer fim, desde que atribua a autoria da obra.

\section{HISTÓRICO}

Recebido em: 12-10-2019

Aprovado em: 11-06-2021 